\title{
Escena familiar de Fernando Botero
}

\author{
Escena familiar by Fernando Botero
}

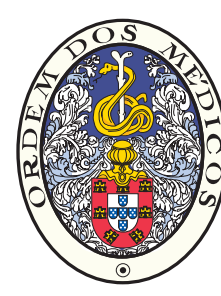

Maria do Céu MACHADO ${ }^{1,2}$

Acta Med Port 2014 Nov-Dec;27(6):799-801

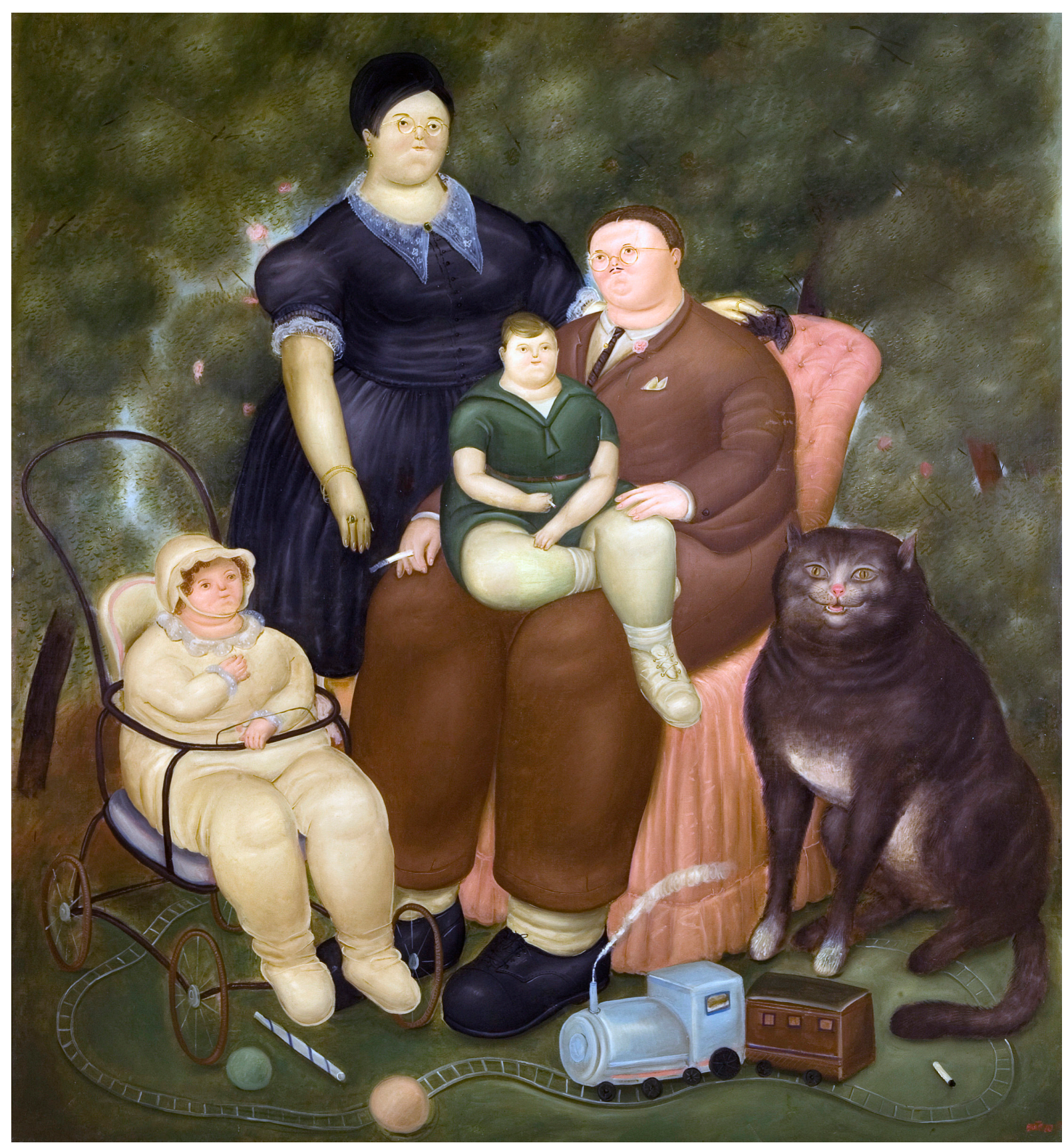

Figura 1 - “Escena Familiar”, Fernando Botero, 1969, Óleo sobre tela, 211 x 195 cm. Fotografia: Museu Colecção Berardo.

1. Departamento de Pediatria. Hospital Santa Maria. Centro Hospitalar Lisboa Norte. Lisboa. Portugal.

2. Clínica Universitária de Pediatria. Faculdade de Medicina. Universidade de Lisboa. Lisboa. Portugal.

Recebido: 05 de Outubro de 2014 - Aceite: 06 de Outubro de 2014 | Copyright @ Ordem dos Médicos 2014 
Palavras-chave: Criança; Excesso de Peso; Obesidade; Pintura. Keywords: Child; Obesity; Overweight; Paint.

Em 1997, o Terreiro do Paço em Lisboa foi invadido pelas enormes esculturas de Fernando Botero, pintor e escultor reconhecido como um dos grandes da América do Sul. E a minha primeira impressão ao olhar para aquelas figuras rotundas e voluptuosas, de cabeças microcéfalas, faces redondas, microftálmicas e micrognáticas, foi de perplexidade perante vultos pouco vibrantes que transmitem a sensação de faltar energia para vencer aquelas toneladas. Exactamente o oposto ao deslumbramento que são as esculturas de Bernini na Villa Borghese, figuras animadas por forças misteriosas.

Nascido em 1932, em Mendellin, nos andes colombianos, cidade que ficou famosa como berço da droga e domicílio de Pablo Escobar, é o segundo filho de três rapazes, educados com dificuldade pela mãe pois o pai morreu quando ele tinha quatro anos. Aos 16 anos, perante gravuras de arte moderna ('não sabia que havia uma coisa chamada arte'), decide que será artista. Frequentava então o colégio de jesuítas de onde foi expulso quando os padres se aperceberam das suas ilustrações de nus para o jornal El Colombiano.

Ainda sem um estilo definido, deslumbra-se com o muralista mexicano Diego Rivera, determinante na dimensão dos seus quadros. As suas primeiras exposições permitiram-Ihe viajar para a Europa e estudar arte em Madrid, Paris e em Florença. Sobrevive, vendendo aos turistas cópias de Ticiano, Velasquez, Goya e Tintoretto.

Em 1957, o trabalho 'Still Life with Mandolin', muda definitivamente a sua perspectiva. Ao desenhar um orifício sonoro do tampo do bandolim, mínimo, quase punctiforme, percebe que isso dá ao objecto uma dimensão inesperada e extraordinária. Insufla então as personagens das suas pinturas, dando-lhes peso e sensualidade rotunda. Reconhecido internacionalmente, expõe em Washington e em Nova lorque em 1958, e todas as peças são vendidas no primeiro dia.

Entre 1966 e 1975 divide o seu tempo pela Greenwich Village (Nova lorque), Baden-Baden (Alemanha) e Bogotá (Colômbia). Sempre mais sintonizado com a Europa, inspirado por Rubens, dá cada vez mais volume às suas criações. As esculturas de metal surgem em 1973, com enormes figuras de animais, dorsos humanos e mulheres reclinadas que expõe em Paris em 1977.

A pintura que me cabe comentar tem o nome de Escena Familiar e representa uma família tradicional com duas crianças, um gato e um comboio de brincar. O homem está sentado numa poltrona pequena com o rapaz sobre a enorme coxa protectora. A mãe em pé e a menina entalada num carrinho de bebé. $O$ felino é também rotundo mas mais equilibrado na relação cabeça/tronco. Até a locomotiva do comboio é pícnica. O quadro não é luminoso mas as cores, verdes e castanhos neutros, de cambiantes múltiplos, têm uma enorme força.

A arte de Botero tem o dom de nos fazer reflectir sobre a obesidade e sobre a família. Em recente artigo do Lan- cet, ${ }^{1}$ o Institute for Health Metrics and Evaluation (School of Medicine, University of Washington, Seattle) publica uma análise exaustiva sobre a prevalência de excesso de peso e obesidade em 188 países, entre 1980 e 2013. O número de pessoas obesas e com excesso de peso mais do que duplicou, de 857 milhões em 1980 para 2,1 mil milhões em 2013, com pico entre 1992 e 2002, no grupo etário entre os 20 e os 40 anos.

O crescimento da epidemia parece ter abrandado nos países desenvolvidos embora se mantenha nos grupos mais desfavorecidos o que se explica pelo crescente recurso a alimentos mais calóricos, com pouco valor nutricional e mais baratos, o que é confirmado por estudo da OCDE, que mostra uma diminuição dos gastos com frutas e vegetais em países como Portugal, Irlanda, a Grécia e a Espanha, entre 2008 e $2013 .{ }^{2}$

Em Portugal, as taxas estão acima das médias da Europa Ocidental: o excesso de peso afecta $28,7 \%$ dos rapazes, $27,1 \%$ das raparigas, $63,8 \%$ dos homens e $54,6 \%$ das mulheres, enquanto a obesidade atinge $8,9 \%$ dos rapazes, $10,6 \%$ das raparigas, $20,9 \%$ dos homens e $23,4 \%$ das mulheres. Também o relatório 'Portugal: Alimentação Saudável em Números 2013', ${ }^{3}$ destaca cerca de $15 \%$ das crianças entre os seis e os nove anos obesa e 35\% com excesso de peso. Mas o update 2014 da OMS mostra uma tendência para a estabilização nos últimos $4-5$ anos, contrariamente ao aumento no Norte da Europa.

Identificam-se facilmente razões próximas, tais como a oferta excessiva, os alimentos hipercalóricos ou a falta de exercício, mas há que procurar raízes mais longínquas para este fenómeno. Segundo a teoria evolucionista de Darwin, somos os sobreviventes de uma espécie exposta ao perigo e à fome. A invenção do fogo e o cozinhar os alimentos são talvez os primeiros passos para a globesity, termo empregue por Delpeuch ${ }^{4}$ para nomear a epidemia de obesidade no contexto da globalização.

Também a voracidade do apetite humano foi determinante para a reengenharia que as empresas alimentares levaram a cabo, estudando rearranjos de açúcar, gordura e sal. Kessler ${ }^{5}$ chama a esta estratégia da indústria alimentar Conditioning hypereating, com efeitos semelhantes ao jogo compulsivo ou ao consumo de drogas. Está provado que não se resiste a uma promoção de uma embalagem de comida com mais $20 \%$ de conteúdo pelo mesmo preço e depois se cozinham maiores quantidades. São conhecidas as consequências quanto ao aumento de doença não crónica nomeadamente diabetes, doenças cardiovasculares e oncológicas.

Alguns países têm legislação apropriada, com aumento das taxas sobre as guloseimas e as bebidas açucaradas. $E$ as autarquias começam a desenvolver estratégias que estimulem andar a pé ou de bicicleta e utilizar os espaços verdes. Mas cada um deve assumir a responsabilidade de ser o gestor da sua saúde.

Nesta matéria, a família é um factor protector e junta na 
mesma estrutura, o património genético e o ambiente, nature and nurture (A Tempestade, Shakespeare, 1610) ou seja a interação entre forças biológicas, genes, e as condições do desenvolvimento.

Mas a taxa de natalidade tem uma quebra histórica, a nível mundial, com o índice sintético de fecundidade a cair de seis para 2,5 filhos por mulher e na União Europeia para 1,58. Em Portugal atinge 1,21 em 2013, valor insuficiente para assegurar a renovação de gerações. ${ }^{6}$

Há menos nascimentos e mais filhos únicos, resultado de múltiplos factores individuais, sociais e económicos. Maiores níveis de educação e de participação das mulheres no mercado de trabalho com implicações na conciliação dos tempos de família, de trabalho e, como consequência, $\mathrm{o}$ adiamento da idade de parentalidade e ainda o aumento da infertilidade, condicionada também pela obesidade, tabagismo e consumo de álcool.

Alteraram-se também os movimentos migratórios. A imigração foi responsável nos anos 90 por um quarto do crescimento da população nos países industrializados e, em Portugal, após as grandes vagas do início do século XXI, houve uma forte desaceleração, de 50 mil novos imigrantes em 2000 para oito mil em 2008. Por outro lado, a sociedade atravessa um período de instabilidade económica e financeira com o emprego dos jovens licenciados como uma das áreas mais afectadas, o que condicionou também a emigração, com 65000 licenciados entre os 24 e os 35 anos a sair de Portugal de Junho de 2012 a Junho de 2013.

A Comissão para a Natalidade (2014), que integro, tem promovido seminários com autarquias, empresas, jovens casais, fiscalistas, profissionais da educação e saúde e apresentou um documento que inclui políticas concertadas envolvendo licenças parentais alargadas, estabilidade e flexibilidade no emprego, creches gratuitas com horários alargados, flexibilidade de trabalho, possibilidade de trabaIhar em casa e criação de bolsas de horas para mãe e pai. $\mathrm{E}$ ainda regulação dos escalões de imposto sobre rendimentos (IRS), imóveis (IMI) e veículos (ISV), electricidade e água, conforme o número de filhos. Não se pretendem consensos mas sim medidas geradoras de compromissos. Sem demagogias, o desequilíbrio entre gerações com aumento da verticalidade das famílias (bisavó-bisneto) tem consequências que não devem ser discutidas apenas sob o ponto de vista da sustentabilidade e das pensões de reforma. A acreditar nas projecções do Instituto Nacional de Estatística, a sociedade estará cada vez mais virada para si do que para as crianças e para o futuro.

\section{AGRADECIMENTOS}

A Acta Médica Portuguesa e a Ordem dos Médicos agradecem ao Museu Colecção Berardo a gentil cedência dos direitos de reprodução deste quadro e a oportunidade de o divulgar.

\section{CONFLITOS DE INTERESSE}

A autora declara a inexistência de conflitos de interesse na realização do presente trabalho.

\section{FONTES DE FINANCIAMENTO}

Não existiram fontes externas.

\section{REFERÊNCIAS}

1. Ng M, Fleming T, Robinson M, Thomson B, Graetz N, Margono C, et al. Global, regional, and national prevalence of overweight and obesity in children and adults during 1980-2013. Lancet. 2014;384:766-81.

2. OECD Obesity update, June 2014; [consultado 2014 Out 03]. Disponível em http://www.oecd.org/health/fitnotfat.

3. Graça P. Portugal: Alimentação saudável em números. Lisboa: DGS; 2013.

4. Delpeuch F, Maire B, Monnier E, Holdsworth M. Globesity: a planet out of control? Earthscan. 2009.

5. Kessler DA. The end of overeating: taking control of the insatiable american appetite. New York: Rodale Inc; 2009.

6. PORDATA. 2014. [consultado 2014 Set 29]. Disponível em http://www. pordata.pt/ 


\section{Escena familiar de Fernando Botero}

Acta Med Port 2014:27:799-801

Publicado pela Acta Médica Portuguesa, a Revista Científica da Ordem dos Médicos

Av. Almirante Gago Coutinho, 151

1749-084 Lisboa, Portugal.

Tel: +351218428 215

E-mail: submissao@actamedicaportuguesa.com

www.actamedicaportuguesa.com

ISSN:0870-399X | e-ISSN: 1646-0758

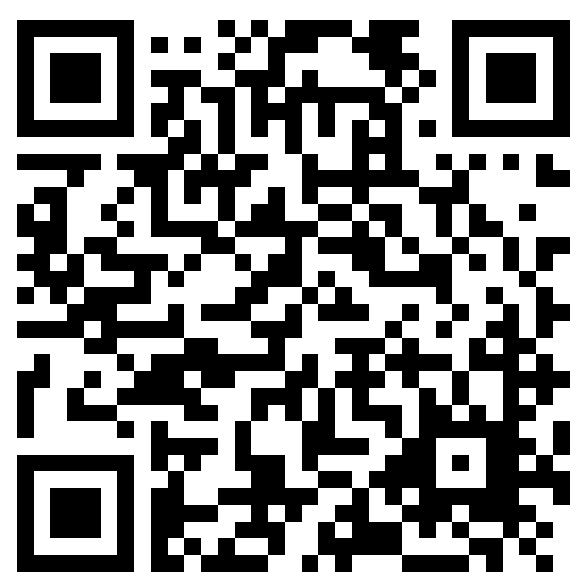

